\title{
Effects of Digesting Chondroitin Sulfate Proteoglycans on Plasticity in Cat Primary Visual Cortex
}

\author{
Vasily Vorobyov, ${ }^{1}$ Jessica C.F. Kwok, ${ }^{3}$ James W. Fawcett, ${ }^{3}$ and Frank Sengpiel ${ }^{1,2}$ \\ ${ }^{1}$ School of Biosciences and ${ }^{2}$ Neuroscience and Mental Health Research Institute, Cardiff University, Cardiff CF10 3AX, United Kingdom, and ${ }^{3}$ Cambridge \\ University Centre for Brain Repair, Cambridge CB2 OPY, United Kingdom
}

Monocular deprivation (MD) during a critical period of postnatal development produces significant changes in the anatomy and physiology of the visual cortex, and the deprived eye becomes amblyopic. Extracellular matrix molecules have a major role in restricting plasticity such that the ability to recover from MD decreases with age. Chondroitin sulfate proteoglycans (CSPGs) act as barriers to cell migration and axon growth. Previous studies showing that degradation of CSPGs by the bacterial enzyme chondroitinase can restore plasticity in the adult rat visual cortex suggest a potential treatment for amblyopia.

Here MD was imposed in cats from the start of the critical period until 3.5 months of age. The deprived eye was reopened, the functional architecture of the visual cortex was assessed by optical imaging of intrinsic signals, and chondroitinase was injected into one hemisphere. Imaging was repeated 1 and 2 weeks postinjection, and visually evoked potentials (VEPs) and single-cell activity were recorded.

Immunohistochemistry showed that digestion of CSPGs had been successful. After 2 weeks of binocular exposure, some recovery of deprived-eye responses occurred when chondroitinase had been injected into the hemisphere contralateral to that eye; when injected into the ipsilateral hemisphere, no recovery was seen. Deprived-eye VEPs were no larger in the injected hemisphere than in the opposite hemisphere. The small number of neurons dominated by the deprived eye exhibited poor tuning characteristics.

These results suggest that despite structural effects of chondroitinase in adult cat V1, plasticity was not sufficiently restored to enable significant functional recovery of the deprived eye.

\section{Introduction}

Amblyopia ("lazy eye") is the commonest disorder of vision in children. It is usually treated by refractive adaptation, followed by either occlusion (patching) therapy or defocus by atropinization of the good eye, thus disadvantaging it for a time to enforce the use of the amblyopic eye (Stewart et al., 2011). The effectiveness of this procedure decreases with age and is typically limited beyond 8 years. Recently, an increasing number of studies has aimed at treating amblyopia in adulthood by means of restoring visual cortical plasticity (Bavelier et al., 2010).

Adult cortical plasticity is suppressed both at a functional level, through the balance of excitation and inhibition, and at a structural level, through inhibition of dendritic motility and neurite growth (Hensch, 2005). The maturation of the extracellular matrix (ECM) plays a crucial role in terminating cortical plasticity (Silver and Miller, 2004; Laabs et al., 2005). Major components of the ECM in the brain are proteoglycans consisting of a

\footnotetext{
Received May 11, 2012; revised 0ct. 3, 2012; accepted Nov. 1, 2012.

Author contributions: J.W.F. and F.S. designed research; V.V. and J.C.F.K. performed research; V.V., J.C.F.K., and F.S. analyzed data; J.W.F. and F.S. wrote the paper.

This work was supported by UK Medical Research Council Grant G0502299. Chondroitinase ABC was a gift from Acorda Therapeutics Inc. (Hawthorne, NY). We are grateful to Clare Galtrey and Wenjun Jin for help with some of the experiments.

J.W.F. is a member of the Scientific Advisor Network of Acorda Therapeutics Inc. who supplied the chondroitinase.

This article is freely available online through the J Neurosci Author Open Choice option.

Correspondence should be addressed to Frank Sengpiel, School of Biosciences, Cardiff University, Museum Avenue, Cardiff CF10 3AX, UK. E-mail: SengpielF@cf.ac.uk.

V. Vorobyov's present address: Institute of Cell Biophysics, Russian Academy of Sciences, Pushchino, Russia.

DOI:10.1523/JNEUROSCI.2283-12.2013

Copyright $\odot 2013$ the authors $\quad 0270-6474 / 13 / 330234-10 \$ 15.00 / 0$
}

protein core with one or more glycosaminoglycan (GAG) chains attached. Chondroitin sulfate proteoglycans (CSPGs) act as barriers to cell migration (Mizuguchi et al., 2003), axon growth (Becker and Becker, 2002), and plasticity, mostly through their GAG chains.

During postnatal development, CSPGs accumulate in particular around inhibitory interneurons, contributing to the formation of "perineuronal nets" (PNNs) (Celio et al., 1998). These structures appear to restrict plasticity in the adult brain (Hockfield et al., 1990). In the visual cortex, their appearance coincides with the end of the critical period (Lander et al., 1997), and dark rearing from birth delays not only the critical period but also the expression of antigens associated with PNNs (Guimarães et al., 1990). Mice with attenuated PNNs display persistent ocular dominance plasticity (Carulli et al., 2010). Some of the inhibitory effects of CSPGs appear to be mediated through the Rho/ROCK pathway (Monnier et al., 2003). Furthermore, there are numerous mechanisms by which the GAG chains may interact with growth-inhibitory molecules, as well as cell surface receptors (Properzi and Fawcett, 2004; Sharma et al., 2012).

These findings suggest that a breakdown of CSPGs may reduce inhibition of neurite outgrowth and permit formation or rearrangement of synapses. Indeed, degradation of CSPGs by the bacterial enzyme chondroitinase $\mathrm{ABC}(\mathrm{ChABC})$, which cleaves the GAG chains, promotes functional recovery after spinal cord injury (Bradbury et al., 2002). Similarly, degradation of CSPGs by chondroitinase restores experience-dependent plasticity in the adult rat visual cortex, such that monocular deprivation (MD) 

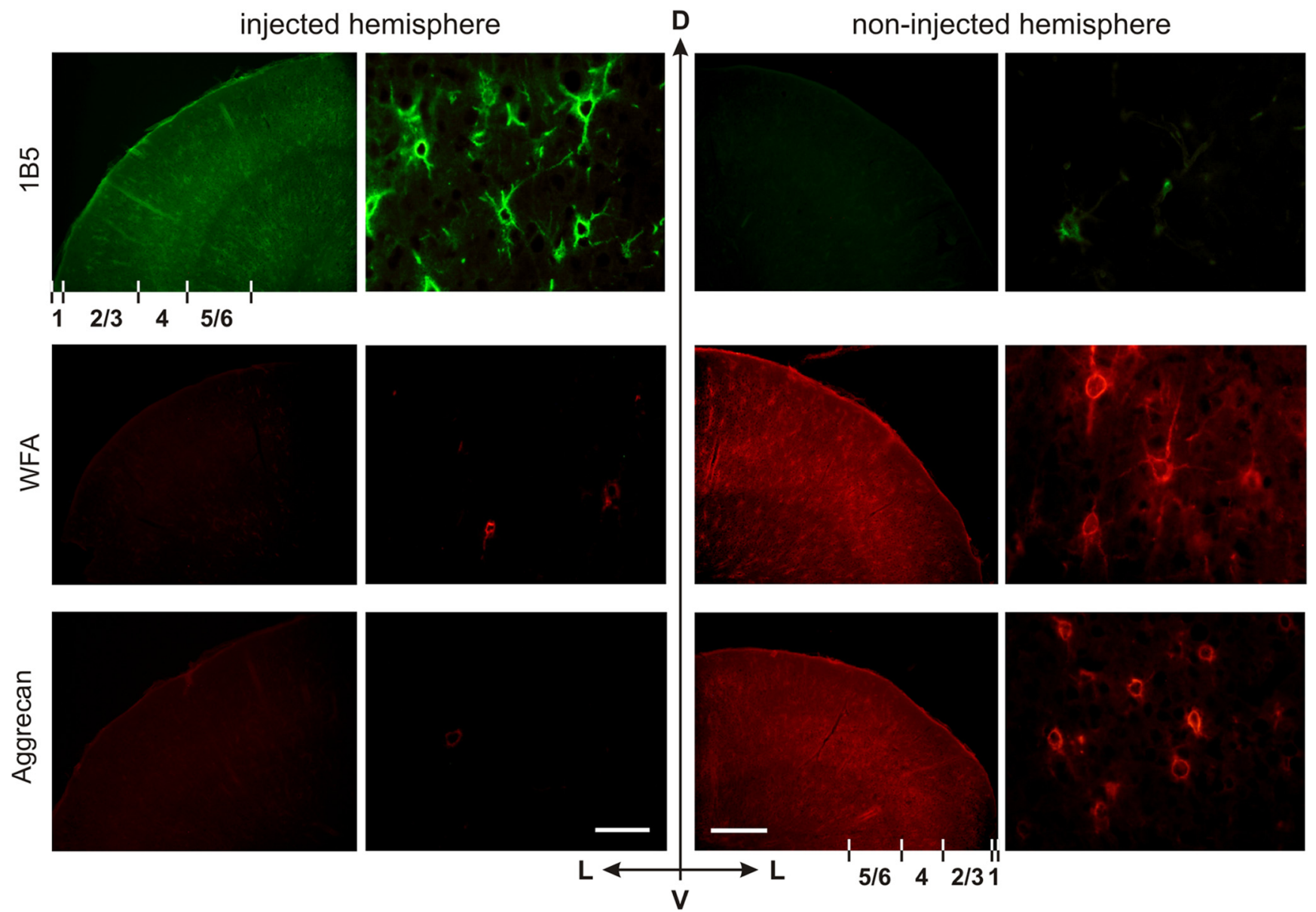

Figure 1. Immunohistochemical evidence for CSPG digestion. Photomicrographs show coronal sections through the primary visual cortex near the apex of the postlateral gyrus of one cat in which the left hemisphere, contralateral to the deprived eye, had been injected with chondroitinase ABC. Arrows indicate orientation ( $D$, dorsal; $V$, ventral; $L$, lateral). The first two columns show images of the injected hemisphere at low magnification (scale bar, $500 \mu \mathrm{m}$ ) and high magnification (scale bar, $50 \mu \mathrm{m}$ ). The third and fourth columns show images of the noninjected hemisphere, again at low and high magnification (scale bars, 500 and $50 \mu \mathrm{m}$, respectively. The top row of images shows the extent of ChABC digestion as revealed by labeling the CSPG stubs with the monoclonal antibody 1B5.While there is very little staining of either neuropil or perineuronal nets in the noninjected hemisphere (right) the injected hemisphere (left) exhibits dense labeling throughout all cortical layers (densest in layer 4; approximate layer boundaries are indicated), as well as intense labeling of PNNs surrounding individual neurons. In contrast, staining for WFA (second row) and aggrecan (third row) both show strong labeling of neuropil and PNNs in the noninjected hemisphere but weak labeling in the injected hemisphere.

imposed after the critical period results in an ocular dominance shift normally observed only in younger animals (Pizzorusso et al., 2002) and rats monocularly deprived during the critical period recover normal ocular dominance if chondroitinase treated in adulthood (Pizzorusso et al., 2006). To translate these results into a potential treatment for humans, we tested this method on cats, a species whose visual cortex has a functional architecture more similar to humans and which develops amblyopia under similar circumstances. We employed optical imaging of intrinsic signals, visual evoked potential, and single-cell recordings to assess functional outcomes.

\section{Materials and Methods}

All procedures were carried out in accordance with UK Home Office regulations on animal experimentation [Animals (Scientific Procedures) Act 1986] and the European Communities Council Directive 86/609/ EEC. Cats of either sex were raised in a normal $12 \mathrm{~h}$ light/dark cycle. At postnatal days (P)20-25 they underwent monocular deprivation by lid suture of the right eye under general anesthesia (ketamine, $20-40 \mathrm{mg} / \mathrm{kg}$ i.m.; xylazine, $2-4 \mathrm{mg} / \mathrm{kg}$ i.m.). Animals continued to be raised in a normal light/dark cycle until at least P90; they were inspected daily to ensure that the deprived eye remained shut.

Optical imaging. All surgical procedures were performed under sterile conditions. Anesthesia was induced with an intramuscular injection of ketamine $(20-40 \mathrm{mg} / \mathrm{kg})$ and xylazine $(2-4 \mathrm{mg} / \mathrm{kg})$. Atropine $(0.2 \mathrm{mg} /$ $\mathrm{kg}$ ) was injected intramuscularly to reduce mucous secretion. Dexamethasone was injected subcutaneously to prevent cortical edema. Animals were intubated orally and ventilated artificially with a mixture of $\mathrm{N}_{2} \mathrm{O}: \mathrm{O}_{2}$ (60:40) and isoflurane (2.0-3.0\%, decreased to $1.2-1.5 \%$ during imaging). Rectal temperature $\left(37.5-38.0^{\circ} \mathrm{C}\right)$, electrocardiogram $(150-200$ beats per minute), and electroencephalogram were monitored throughout the experiment, and adequate measures taken if any of the values diverged from the targets. A $4 \%$ glucose in saline solution was infused i.v. at $3 \mathrm{ml} / \mathrm{kg} / \mathrm{hr}$ throughout the experiment.

The previously deprived eye was reopened; atropine and phenylephrine were administered to both eyes, which were fitted with gaspermeable contact lenses to protect them and to focus the animal's vision onto the stimulus display, a 21 " monitor positioned at a distance of $50 \mathrm{~cm}$.

Optical imaging of primary visual cortex was performed as described previously (Bonhoeffer and Grinvald, 1996; Schwarzkopf et al., 2007). The scalp was incised and retracted; a rectangular craniotomy was performed above area 17 in both hemispheres. A titanium chamber was cemented to the skull and sealed on the inside with dental wax. The chamber was filled through an inlet with sterile silicon oil (dimethylpolysiloxane, Sigma-Aldrich) and closed with a glass coverslip. In addition, a head holder was cemented to the skull.

Initially, the exposed brain was illuminated with green light, and a reference image of the surface vascular pattern was taken. Subsequently, 
the cortex was illuminated with red light at 700 $\mathrm{nm}$. Images were captured using an enhanced differential imaging system (Imager 2001, Optical Imaging) with the camera focused $500 \mu \mathrm{m}$ below the cortical surface. Visual stimuli were produced by a stimulus generator (VSG Three, Cambridge Research Systems), and consisted of high-contrast (mean luminance, $38 \mathrm{~cd} / \mathrm{m}^{2}$ ), sinusoidally modulated gratings of two spatial frequencies [0.1-0.75 cycles/degree (c/deg)] and four different orientations $\left(0,45,90\right.$, and $\left.135^{\circ}\right)$ drifting at $2 \mathrm{~Hz}$. These stimuli were presented separately to the two eyes using computercontrolled shutters in randomized sequence and interleaved with trials in which the screen was blank. Image acquisition lasted for $2 \mathrm{~h}$.

Single-condition responses for each eye were divided (1) by responses to the blank screen, and (2) by the sum of responses to all four orientations ("cocktail blank") to obtain isoorientation maps. These were then bandpass filtered and range fitted for display purposes, and orientation angle maps were obtained by vectorial addition, on a pixel-by-pixel basis, of the four iso-orientation maps (Bonhoeffer and Grinvald, 1996).

To quantify cortical territory occupied by the two eyes, for each hemisphere a region of interest (ROI) was defined using Interactive Data Language (IDL) software (Research Systems), excluding blood vessel and other artifacts (Bonhoeffer et al., 1995). Ocular dominance maps were calculated by dividing all responses to one eye by the responses to the other. The signal used for subsequent quantitative analysis was reflectance change $(\Delta R / R)$ for each pixel given at 16-bit precision. For analysis of the relative strength of responses through the two eyes, images were only low-pass filtered (smoothed), For analysis of areas responding preferentially through one or the other eye, images were additionally high-pass filtered well above the periodicity of ocular dominance domains (cutoff, 200 pixels $=7.8 \mathrm{~mm}$ ) to level the image intensity across the region of interest. Within the ROI, pixels were assigned to the left and right eye, respectively, depending on whether their response ratio was $>1$ or $<1$. The numbers of pixels responding more strongly to the left and the right eye, respectively, were calculated for each hemisphere. For illustrations, signals were range fitted such that the 1.5\% most responsive (least responsive) pixels were set to black (white), and Gaussian averaging over six pixels was applied to remove high-frequency noise. Signal amplitude was displayed on an 8-bit gray scale.

Chondroitinase treatment. After completion of the optical imaging session, a durotomy was performed (on both cortical hemispheres). Two to three injections at $1 \mu \mathrm{l}$ each of $\mathrm{ChABC}$ at a concentration of $100 \mathrm{U} / \mathrm{ml}$ in $0.9 \%$ sterile saline with $0.1 \%$ BSA were made into V1 of one hemisphere as follows. A $5 \mu$ l Hamilton syringe with a $33 \mathrm{G}$ needle was positioned stereotaxically above the imaged region by means of a 3 axis micromanipulator (David Kopf Instruments). A hydraulic microdrive (Narishige) was adapted to slowly push the plunger down under visual control. Injections were spaced about 2-3 mm apart. At each location, $0.5 \mu \mathrm{l}$ of ChABC was injected at two different depths, about $500 \mu \mathrm{m}$ and $1000 \mu \mathrm{m}$ below the surface, and the needle was left in place for $5 \mathrm{~min}$ before withdrawal. The imaging chamber was then sealed, the animal treated with systemic antibiotics ( $0.1 \mathrm{ml}$ of Metacam, Boehringer-Ingelheim) and analgesics ( $0.1 \mathrm{ml}$ of Ketofen, Merial); these injections were given prophylactically for 5 days. Anesthesia was withdrawn, and after a full recovery the animal was returned to its home cage. After 1 week and again after 2 weeks the animal was imaged under general anesthesia as described above. After the final imaging session, VEP and single-cell recordings were carried out.

VEP recording. After imaging data acquisition was completed, the chamber was reopened and the silicone oil was replaced with saline for
VEP recording (for details, Howarth et al., 2009). The animal was paralyzed with gallamine triethiodide $(10 \mathrm{mg} / \mathrm{kg} / \mathrm{h}$ Sigma-Aldrich) for prevention of eye movements. A silver ball electrode was placed on the surface of the primary visual cortex. The recorded signal was amplified and low-pass filtered (cutoff, $300 \mathrm{~Hz}$ ). Recordings were made from both hemispheres in corresponding locations. Stimuli were displayed on a computer screen and consisted of high contrast, phase-reversing, square wave horizontal gratings that varied only in spatial frequency. Gratings reversed contrast at a rate of $1 \mathrm{~Hz}$. A blank screen was used to measure the baseline response. Stimuli were presented to the left and right eyes separately for $3 \mathrm{~s}$, corresponding to six contrast reversals, with interstimulus intervals of $3 \mathrm{~s}$. Responses were averaged across the six contrast reversals per presentation and across 20 presentations of each stimulus using software written in LabVIEW (National Instruments). The resulting signals therefore constituted the responses to 120 contrast reversals each per stimulus. The total amplitude of the VEP signal was defined as the difference in voltage between the signal peak and the subsequent trough within a $500 \mathrm{~ms}$ window.

Electrophysiology. In all experimental animals, we determined quantitative orientation/direction tuning curves of single units recorded with glass-insulated tungsten microelectrodes and discriminated by their spike shapes using BrainWare software (Tucker-Davis Technologies). Left and right eye responses to drifting sinusoidally modulated gratings (of optimum spatial frequency) of 16 different directions in $22.5^{\circ}$ steps were averaged over 5 trials of $1.5 \mathrm{~s}$ duration. Gaussian tuning curves were fitted to the data points, and preferred orientation and half-width of tuning at half-height were determined from these curves. Ocular dominance $(\mathrm{OD})$ categories were assigned to each neuron based on the ratio of the mean responses to deprived eye (DE) and nondeprived eye (NE) stimulation, calculated as ( $\mathrm{DE}-\mathrm{NE}) /(\mathrm{DE}+\mathrm{NE})$. This yields values between -1 and 1 , which we divided into seven equal intervals to define OD categories (Hubel and Wiesel, 1962).

External stimulus control, data acquisition, and analysis were performed by TDT System II using BrainWare software (Tucker-Davis Technologies). Neuronal activity was recorded extracellularly with glassinsulated tungsten microelectrodes (Ainsworth), which were advanced 
into V1 perpendicularly to the cortical surface by means of a stepper motor microdrive (EPS electrode positioning system; Alpha Omega Engineering). This allowed four electrodes to be inserted simultaneously but advanced independently of each other. Recordings were made from neurons throughout the depth of V1. Precise locations of each penetration site were chosen after superimposing the blood vessel patterns on ocular dominance maps obtained in the preceding imaging session. We targeted left and right eye domains on the chondroitinase injected as well as on the control hemisphere. Single units were discriminated by their spike shapes.

Immunohistochemistry. After completion of all data acquisition, animals were euthanized and perfused with $4 \%$ paraformaldehyde in phosphate buffer and brains were postfixed for two hours before being placed in $30 \%$ sucrose in PBS.

In all animals the effectiveness of the treatment was controlled by histochemistry as described (Pizzorusso et al., 2002). Forty micrometer transverse sections from the occipital cortex were cut on a sledge microtome and collected in PBS. Free-floating sections were treated with blocking solution (3\% normal horse serum, $0.3 \%$ Triton X-100 in $1 \times$ PBS) and incubated overnight at $4^{\circ} \mathrm{C}$ in the monoclonal CSPG stub antibody $1 \mathrm{~B} 5$ (1:400; Seikagaku, product no. 270431). This was then revealed with 1:500 anti-mouse Alexa Fluor $488 \mathrm{~nm}$ (Invitrogen). Alternating sections were treated 1:200 with biotinylated Wisteria floribunda agglutinin (WFA; Sigma L1516) and then with 1:500 streptavidin-Alexa Fluor $568 \mathrm{~nm}$ (Invitrogen) or 1:400 monoclonal anti-aggrecan antibody (Millipore Bioscience Research Reagents, catalog no. MAB5284), followed by 1:500 anti-mouse Alexa Fluor $568 \mathrm{~nm}$ (Invitrogen). Images were taken with a Leica Leitz DMRB microscope with a Nikon DMX1200 camera.

\section{Results}

Successful digestion of CSPGs was verified in all ChABC-injected hemispheres by means of immunohistochemistry (Fig. 1). Individual injections resulted in digestion of CSPG side chains, leaving stubs that were then labeled with monoclonal antibody 1B5 in an area of about $1-1.5 \mathrm{~mm}$ radius around the injection site and extending throughout all cortical layers. In all animals the extent of digestion covered the area studied by optical imaging. Stub staining revealed CSPG cleavage both in the neuropil and in perineuronal nets surrounding individual neurons. Staining was densest in layer 4, mirroring aggrecan staining of the noninjected hemisphere (see below, this paragraph), but labeled neurons were otherwise randomly distributed within each layer. To quantify ChABC activity, we counted the number of 1B5-positive cells in five fields of view $(300 \mathrm{~mm} \times 200 \mathrm{~mm})$ in each of five sections per animal from both the ChABC-injected and the noninjected hemispheres. On the injected side we counted $10.507 \pm 0.730$ cells (mean \pm SD), and on the noninjected side we found $1.253 \pm$ 0.679 cells per field; this difference was highly significant $(p<$ 0.001 , homoscedastic $t$ test). To assess the effectiveness of digestion we further stained alternating sections for WFA and for aggrecan, the main target of chondroitinase activity. In agreement with previous work (Kind et al., 2012), aggrecan immunoreactivity was strongest in layer 4. Staining was drastically reduced in the chondroitinase-injected hemisphere compared with the noninjected hemisphere. Quantitatively, the number of aggrecanpositive cells was $1.373 \pm 0.372$ cells per field (mean \pm SD) in the injected hemisphere compared with $9.133 \pm 0.588$ cells in the noninjected hemisphere. This highly significant difference $(p<$ 0.001 , homoscedastic $t$ test) corresponded to a decrease by $85.0 \%$, demonstrating the effectiveness of chondroitinase action.

\section{Imaging of cortical maps}

Functional maps of both hemispheres of V1 were obtained by means of intrinsic signal imaging (1) immediately after reopening the deprived eye just before chondroitinase injection, (2) 1 week after the injection, and (3) 2 weeks after the injection. Oc-
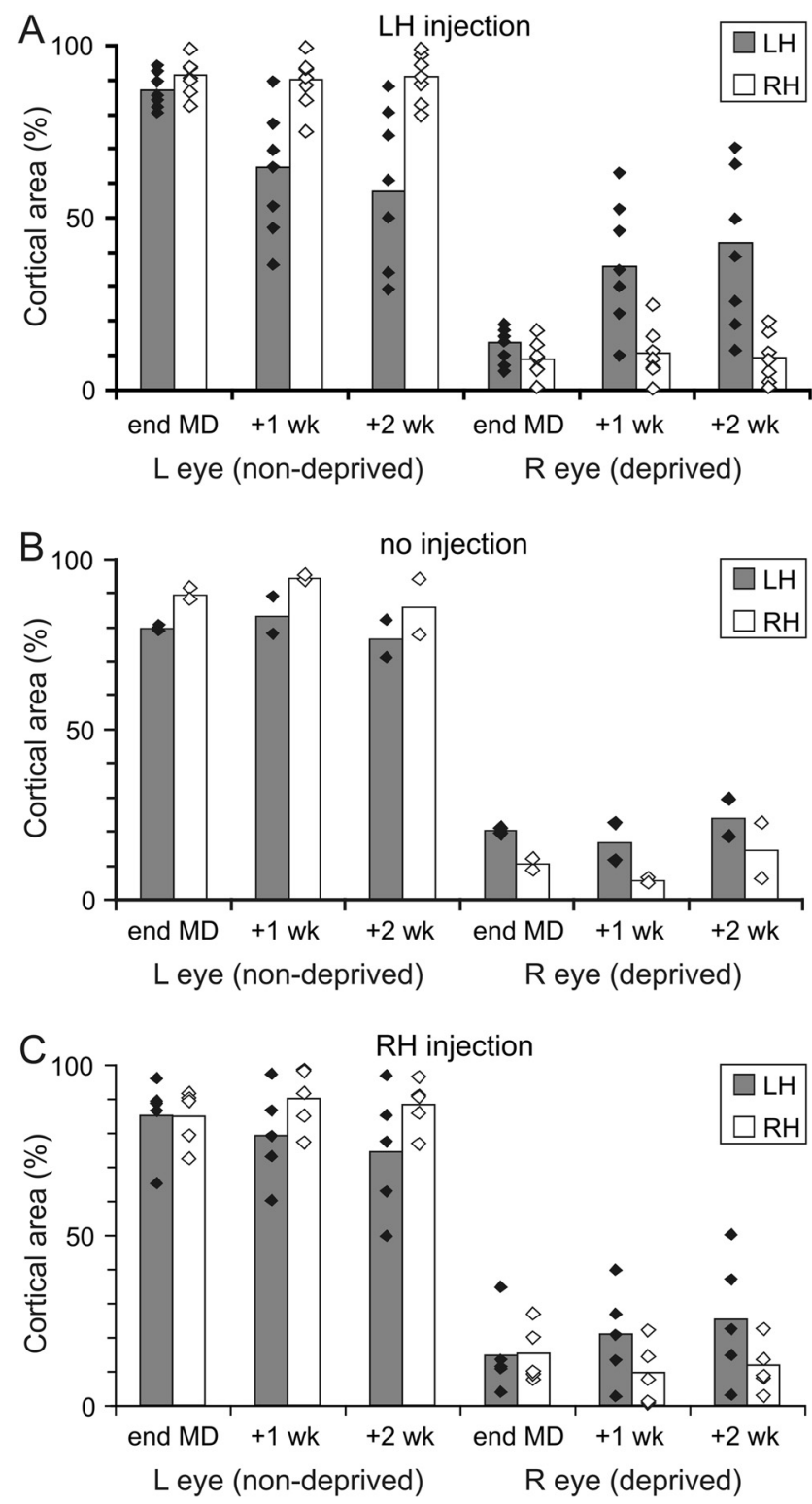

Figure 3. Cortical areas responding to deprived and nondeprived eye stimulation in both hemispheres of $\mathrm{V} 1$. $\boldsymbol{A}$, Mean areas ( \pm SEM) of left $(\mathrm{L})$ and right $(\mathrm{R})$ eye responses before chondroitinase injection into the left hemisphere (contralateral to the deprived eye) 1 week (wk) later and 2 weeks later. Gray bars give results for the left (injected) hemisphere $(\mathrm{LH})$, and white bars give results for the right (untreated) hemisphere (RH). $\boldsymbol{B}$, Mean areas ( \pm SEM) of left and right eye responses at the time of reopening of the deprived eye ("end $\mathrm{MD}^{\prime}$ ), one week later and 2 weeks later. $\boldsymbol{C}$, Mean areas ( \pm SEM) of left and right eye responses before chondroitinase injection into the right hemisphere (ipsilateral to the deprived eye) 1 week later and 2 weeks later.

ular dominance and orientation preference maps were obtained at all three time points from seven cats in which the hemisphere contralateral to the deprived eye had been injected with ChABC, five cats in which the ipsilateral hemisphere had been injected, and two cats that had not been injected.

Previous studies have shown that, even after just 7-10 days of MD near the peak of the critical period, deprived eye responses become restricted to patches occupying about $20 \%$ of the cortical surface and orientation preference maps can no longer be obtained for the deprived eye (Crair et al., 1997; Gillespie et al., 2000; Faulkner et al., 2005; Jaffer et al., 2012).

Ocular dominance maps from one representative cat in which the hemisphere contralateral to the deprived eye had been in- 
jected with ChABC are illustrated in Figure 2. As expected, after prolonged monocular deprivation both hemispheres of $\mathrm{V} 1$ were strongly dominated by the nondeprived (left) eye and virtually no activity could be elicited through the deprived (right) eye. One week later, some deprived eye responses could be observed in the contralateral (left) hemisphere, and these remained essentially unchanged after a further week. In contrast, in the noninjected ipsilateral hemisphere only minimal responses were seen at both at 1 week and 2 weeks after reopening of the deprived eye.

For the seven animals in which the left hemisphere contralateral to the deprived eye had been injected with ChABC, the mean deprived eye territory increased from $13.2 \pm 2.0 \%$ SEM) on the day of the chondroitinase injection to $37.3 \pm 6.9 \%$ after 1 week and $40.5 \pm$ $8.6 \%$ after 2 weeks (Fig. $3 A$ ). These increases were significant (both $p<0.05$, paired $t$ test). For the ipsilateral (noninjected) hemisphere, no significant changes in deprived eye territory were observed $(8.6 \pm 2.1 \%$ after eye opening, $10.2 \pm$ $4.0 \%$ after 1 week, and $9.0 \pm 2.7 \%$ after 2 weeks; both $p>0.1$, paired $t$ test).

The recovery of deprived eye responses in the contralateral hemisphere could have occurred independently of any chondroitinase action simply through residual cortical plasticity promoted by binocular vision (Mitchell et al., 2001). We therefore analyzed two animals in which neither hemisphere had been treated with chondroitinase and found that responses through the formerly deprived eye changed little over 2 weeks after reopening. In the contralateral hemisphere, responsive areas were $20.3 \%$ after reopening of the deprived eye, $16.8 \% 1$ week later, and $23.7 \% 2$ weeks later, while for the ipsilateral hemisphere the corresponding values were 10.4, 5.6, and 14.4\%, respectively (Fig. $3 B$ ). In addition, we examined five cats in which the ipsilateral hemisphere was treated with ChABC, one of which is illustrated in Figure 4. Although in this case we observed some areas of deprived eye response in the contralateral (noninjected) hemisphere, these appeared to be qualitatively weaker than those in the animals where that hemisphere had been injected with chondroitinase. Notably, the treated ipsilateral hemisphere exhibited only very weak deprived eye responses.

For the five animals in which the right hemisphere ipsilateral to the deprived eye had been injected with chondroitinase, the mean area dominated by that eye in the injected hemisphere was $15.3 \pm 3.7 \%$ SEM after eye opening, $9.8 \pm 4.0 \%$ one week later, and $11.7 \pm 3.3 \%$ after a further week (Fig. $3 C$ ). None of the changes were significant $(p>0.05$, paired $t$ test). For the hemisphere contralateral to the deprived eye, the area dominated by that eye increased slightly from $14.9 \pm 5.1 \%$ SEM at the end of the deprivation period to $20.8 \pm 6.2 \% 1$ week later and $25.6 \pm 8.2 \%$ 2 weeks later; however, these increases were not significant $(p>$ 0.05 , paired $t$ test).

In terms of true functional recovery, the selectivity of neuronal responses through the formerly deprived eye is as important as the territory occupied by that eye. We therefore analyzed iso-orientation maps obtained through either eye and found that although there were small areas of response to deprived eye stimulation both before chondroitinase injection and 1 or 2 weeks later, their location did not vary with grating orientation (Fig. $5 A$ ). When iso-orientation maps were divided by the so-called cocktail blank (the sum of responses to all orientations; Bonhoeffer and Grinvald, 1993) to remove nonselective response components from the images, they became flat (Fig. $5 B$ ) In other words, there were no orientation selective responses, and this held true for both injected and noninjected hemispheres (Fig. 5). Accordingly, composite orientation preference maps obtained by vectorial addition of individual iso-orientation maps were essentially flat for the deprived eye in all animals and hemispheres, while the nondeprived eye maps exhibited the typical pinwheel layout (Bonhoeffer and Grinvald, 1993).

\section{VEP recordings}

As a physiological measure of visual acuity (Berkley and Watkins, 1973; Campbell et al., 1973; Harris, 1978), we analyzed VEPs in response to gratings of a range of spatial frequencies in the seven cats in which the hemisphere contralateral to the deprived eye had been treated with chondroitinase. Previous studies have shown that long-term MD virtually eliminates VEPs through the deprived eye across all spatial frequencies (Snyder and Shapley, 1979; Baro et al., 1990). Responses from a representative animal are shown in Figure $6 A$, and mean responses for all seven animals in Figure $6 \mathrm{~B}$. We only occasionally observed weak deprived eye responses to the lowest spatial frequency tested $(0.14 \mathrm{c} / \mathrm{deg})$, and these were no stronger and no more consistent for the contralateral hemisphere than for the ipsilateral hemisphere. Similarly, no significant VEP responses were measured at any spatial frequency for either hemisphere in the five cats in which chondroitinase had been injected ipsilaterally to the deprived eye (Fig. 6C).

\section{Single-cell recordings}

Since optical imaging of both intrinsic signals and VEPs represents the responses of many neurons and therefore the responses of a minority of stimulus-selective deprived eye responses could be swamped, we recorded from individual neurons in both treated and untreated hemispheres of all animals. We targeted electrode pene- 


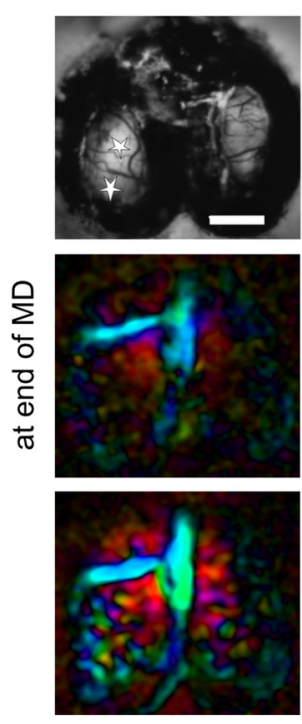

B
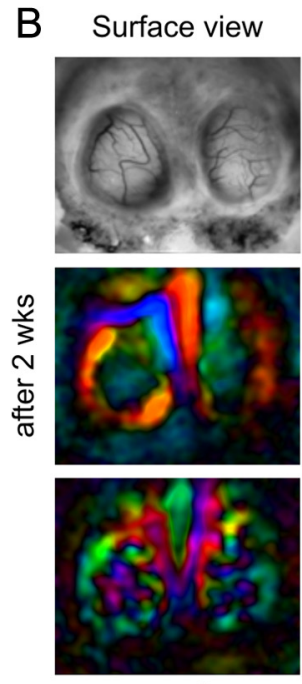

$->/ I N$
A Surface view $0^{\circ}$ maps
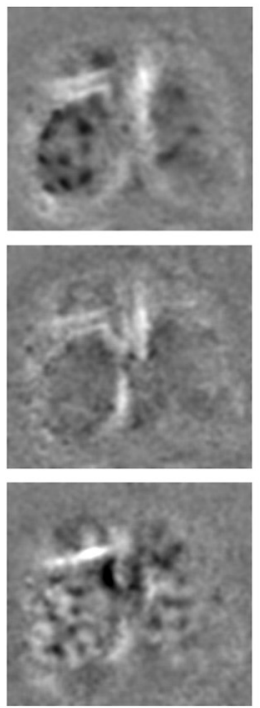

$0^{\circ}$ maps
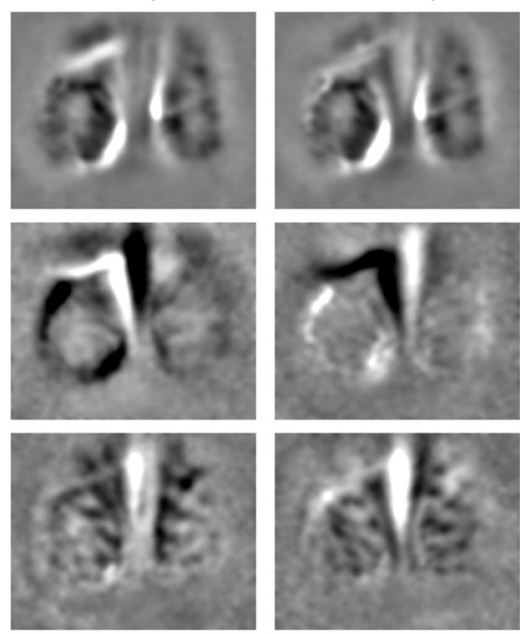

$90^{\circ}$ maps
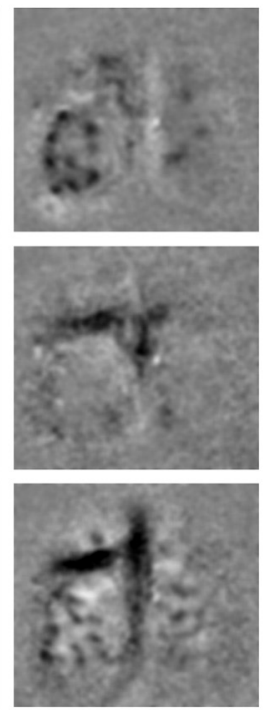

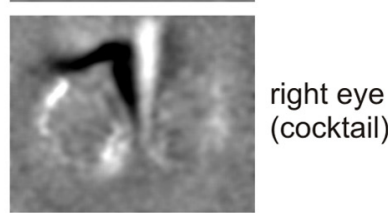

Figure 5. Orientation maps in an animal in which the left hemisphere contralateral to the deprived eye had been injected with chondroitinase. $A$, Maps obtained at the end of the deprivation period. The top row shows the surface view of the dorsal part of the primary visual cortex on the day when the deprived right eye was reopened and the left hemisphere was injected (stars mark injection sites). It then shows iso-orientation maps for right (deprived) eye responses to horizontal $\left(0^{\circ}\right)$ gratings and vertical $\left(90^{\circ}\right)$ gratings normalized by subtraction of the response to a gray screen ("blank"). Dark regions indicate areas of response. On the left the second row shows the "polar" orientation preference map obtained by vectorial addition of responses to gratings of $0,45,90$, and $135^{\circ}$, where the hue indicates each pixel's preferred orientation, and the brightness indicates its selectivity for orientation. The middle and right images show iso-orientation maps for right (deprived) eye responses to 0 and $90^{\circ}$ gratings normalized by subtraction of the response to the cocktail blank (the sum of responses to all orientations through that eye). The third row shows, on the left, the "polar" orientation preference map for the left (nondeprived) eye. The second and third images show isoorientation maps for left eye responses to 0 and $90^{\circ}$ gratings normalized by subtraction of the response to the cocktail blank. $\boldsymbol{B}$, Maps obtained from the same animal 2 weeks later; all conventions as in $A$. Arrows indicate orientation ( $A$, anterior; $R$, right). Scale bar, $2 \mathrm{~mm}$.

trations perpendicular to the cortical surface equally at regions of deprived eye response and those dominated by the nondeprived eye. Despite this approach, of a total of 306 cells recorded from injected hemispheres only 43 (or 14.1\%) were dominated by the deprived eye, indicating that even near regions identified as responsive to the deprived eye, many neurons were dominated by the other eye. Cells dominated by the deprived eye typically displayed broad orientation tuning, as illustrated in Figure 7A, while those dominated by the nondeprived eye were mostly orientation selective (Fig. 7B). The right eye

(blank)

right eye

(cocktail)

left eye

(cocktail)

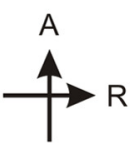

right eye

(blank)

left eye

(cocktail)

latter had a mean half-width of tuning of $28.0 \pm 0.7^{\circ} \mathrm{SEM}$, while the former had a mean half-width of $\left.43.0 \pm 3.4^{\circ} \mathrm{SEM}\right)$. The difference between the two populations was highly significant ( $p<0.001$, heteroscedastic $t$ test). To ascertain whether the injection per se had an effect on neuronal responses, we also analyzed the responses of 89 neurons from the untreated hemisphere. For 78 cells dominated by the nondeprived eye the orientation tuning half-width was $29.6 \pm$ $1.5^{\circ} \mathrm{SEM}$, which was not significantly different from those cells recorded from the treated hemisphere ( $p>0.1$, homoscedastic $t$ test). However, the tuning of 11 cells (or $12.4 \%$ of the total) dominated by the deprived eye was, at $65.4 \pm 7.7^{\circ} \mathrm{SEM}$, significantly wider than that of the 42 cells recorded from the treated hemisphere ( $p<$ 0.01 , homoscedastic $t$ test), suggesting that chondroitinase treatment led to some improvement in orientation selectivity.

In addition to orientation tuning, we assessed spatial frequency tuning with gratings of a range of spatial frequencies presented at each cell's optimal orientation and found that responses of cells dominated by the deprived eye (Fig. 8A) generally peaked at lower frequencies than those dominated by the nondeprived eye (Fig. 8 $B)$. The geometric mean of the cutoff frequency of 201 cells recorded from the injected hemisphere and dominated by the nondeprived eye was $2.10 \mathrm{c} / \mathrm{deg}$, and the geometric mean of the cutoff of 37 cells dominated by deprived eye was $1.22 \mathrm{c} / \mathrm{deg}$. For statistical purposes we transformed the cutoff values logarithmically and found that deprived eye and nondeprived eye cutoffs differed significantly ( $p<0.001$, heteroscedastic $t$ test). In contrast, there was no difference between cutoffs of the 201 cells dominated by the nondeprived eye and recorded from the treated hemisphere and cutoffs from the 60 neurons recorded from the untreated hemisphere (geometric mean cutoff, $2.15 \mathrm{c} / \mathrm{deg}$ ).

\section{Discussion}

In long-term monocularly deprived cats, digestion of CSPG GAG side chains by chondroitinase promoted a moderate recovery of visual cortical responses through the deprived eye. In the hemisphere ipsilateral to the deprived eye chondroitinase treatment appeared to have no effect, whereas in the hemisphere contralateral to the deprived eye chondroitinase injection resulted in a greater increase in territory responding to stimulation of that eye than simple reopening of the eye without treatment. However, the responsive areas largely lacked orientation selectivity, and this was reflected in much broader orientation tuning of single-neuron responses through the deprived eye compared with the nondeprived eye. Moreover, the cutoff point 
of spatial frequency tuning of deprived eye-dominated neurons was significantly reduced relative to neurons driven by the nondeprived eye. Visually evoked potentials were largely absent through the deprived eye in both treated and untreated cortical hemispheres. The apparent discrepancy between a moderate recovery of intrinsic optical signals in response to deprived eye stimulation and the lack thereof in the VEPs indicates that input from the formerly deprived eye is being processed in V1 without resulting in much suprathreshold activity that would be reflected in VEPs or a larger number of deprived eye-driven neurons. Only about $50 \%$ of the energy expenditure that drives hemoglobin deoxygenation as a major source of the optical signal (Frostig et al., 1990) is due to action potentials (Attwell and Laughlin, 2001).

The limited scope of recovery from long-term MD in cats contrasts with a report on rats where chondroitinase treatment not only restored a normal ocular dominance distribution among single neurons and normal VEPs recorded from V1, but also resulted in normal behavioral visual acuity in the previously deprived eye (Pizzorusso et al., 2006). One difference between that study and ours is the fact that Pizzorusso et al. (2006) sutured the nondeprived eye at the time of the reopening the deprived eye. However we do not believe that this can account for the discrepant outcomes; in fact, in kittens recovery from a brief period of MD is faster when both eyes are open (as was the case in our study) than when reverse lid suture is carried out (Mitchell et al., 2001). More importantly, when binocular vision is restored in cats following reverse occlusion, the initially deprived eye in most cases suffers a loss in acuity while the initially open eye does not recover normal acuity, resulting in bilateral amblyopia (Mitchell et al., 1984; Murphy and Mitchell, 1986). When comparing the extent of recovery from MD between rats and cats it has to be borne in mind that the two species differ significantly in the severity of the effects of MD in the first place. In particular, the reduction in VEP cutoff point and visual acuity (each by about two-thirds of an octave, from 1.1 to $0.7 \mathrm{c} / \mathrm{deg}$; Pizzorusso et al., 2006) is rather modest compared with the dramatic loss of vision observed in kittens monocularly deprived for similar periods who become blind in the deprived eye (acuity $<0.1 \mathrm{c} / \mathrm{deg}$ ) compared with a normal acuity of around 6-7 c/deg (Mitchell, 1991), equivalent to a reduction by at least six octaves. It appears that the scope for ocular dominance plasticity during the critical period is greater in cats than in rodents, which may not be surprising given the much higher degree of binocularity. On the other hand, residual "adult" plasticity after the end of the classical critical period is much greater in rodents (Sawtell et al., 2003) than in cats, which may explain why there is more capacity for recovery from long-term MD in the former than in the latter. Another important species difference is the presence and absence of OD columns in cats and rodents, respectively. The segregation of left eye and right eye afferents in cats may limit interactions to near column boundaries, and this may either reduce the scope for reorganization or slow it down. Although in our study there were no obvious differences in recovery of deprived eye responses 1 or 2 weeks after chondroitinase treatment, and although it has previously been shown that while chondroitinase remains active for at least 10 days postinjection neurocan is again being glycanated after 7 days (Lin et al., 2008), it cannot be ruled out that after a longer and/or repeated treatment, recovery might have been greater. In addition, it has to be borne in mind that the cellular mechanisms underpinning adult plasticity in rodents are qualitatively different from those operating during the critical period (Frenkel and Bear, 2004; Sato and Stryker, 2008; Ranson et al., 2012) and might
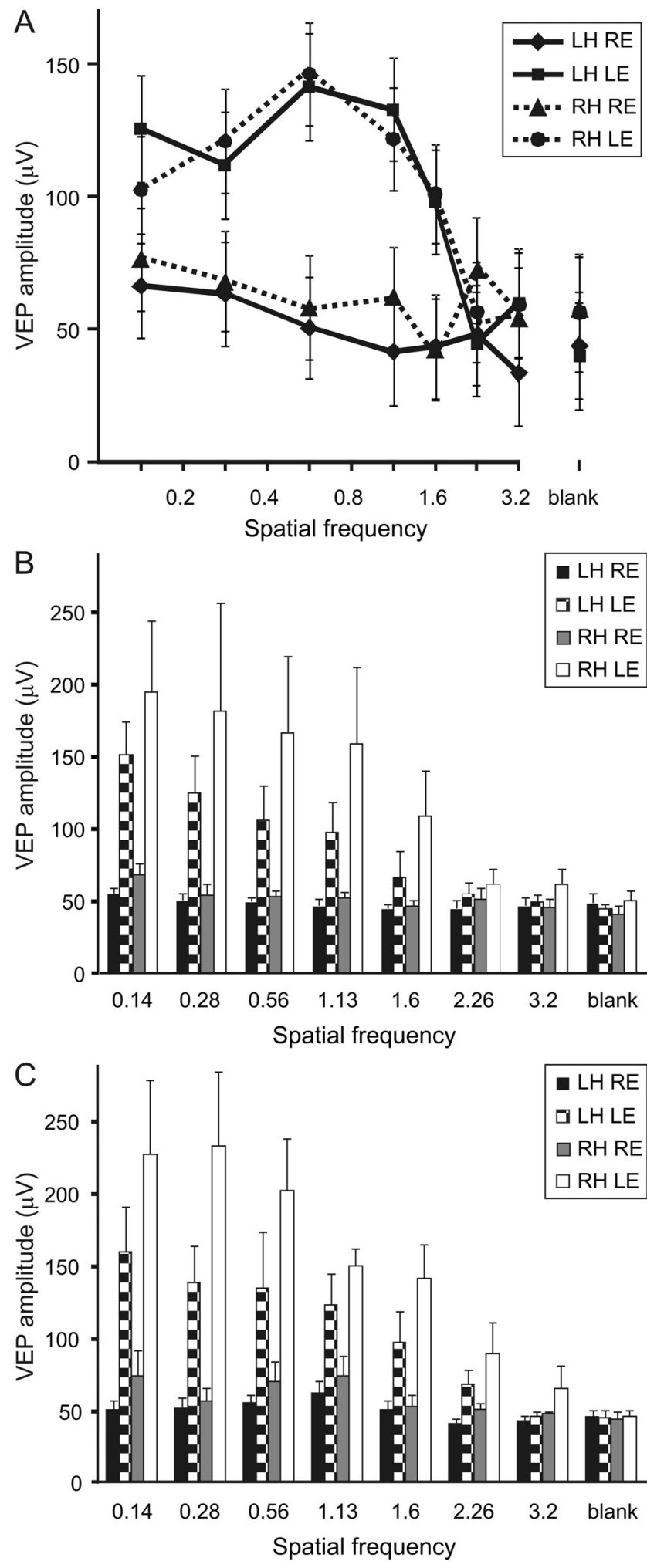

Figure 6. VEPs in response to contrast-reversing gratings of different spatial frequencies. $A, A m$ plitude ofVEPs recorded from one cat in which the righthemisphereipsilateral to the deprived eye had been injected with chondroitinase. The responses through the left nondeprived eye (LE) exhibit a cutoff at $2.26 \mathrm{c} / \mathrm{deg}$ for both the left hemisphere (LH) and the right hemisphere (RH). Responses through the right eye (RE) were not significantly different from those to a blank screen in either hemisphere. $\boldsymbol{B}$, VEP amplitudes averaged across five animals in which the right hemisphere ipsilateral to the deprived eye had been injected with chondroitinase. Mean amplitudes ( \pm SEM) are plotted against the spatial frequency of the test gratings for both the left, nondeprived eye and the right, deprived eye. C, VEP amplitudes averaged across seven animals in which the left hemisphere contralateral to the deprived eye had been injected with chondroitinase; all conventions as in $\boldsymbol{B}$. 

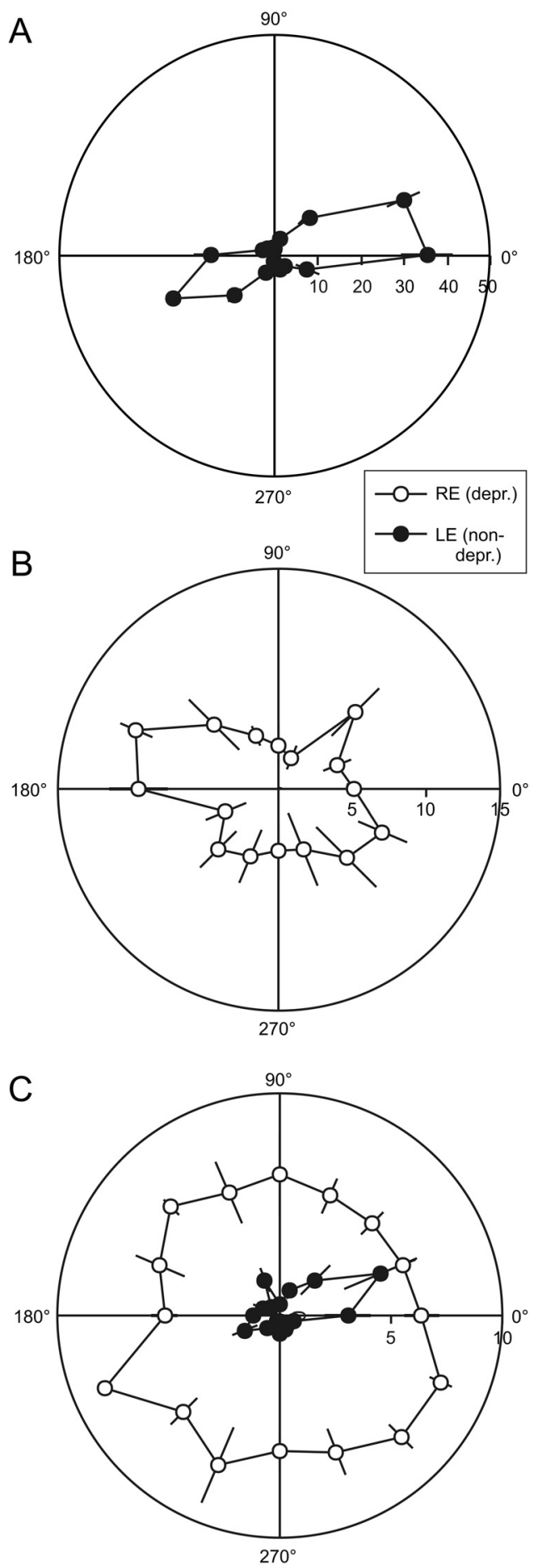

Figure 7. Orientation tuning of single neurons recorded in the injected hemisphere. $A$, Responses of a simple cell dominated by the left, nondeprived (non-depr.) eye (LE) recorded from the left hemisphere. The polar plot displays the response (in spikes/s) against the direction of drift of the grating stimulus ( $0^{\circ}$ denotes a horizontal grating drifting up). Error bars represent SEM. This cell had a tuning half-width of $24^{\circ}$. B, Responses of a complex cell dominated by the right deprived (depr.) eye (RE) recorded from the left hemisphere. This cell had a tuning half-width of $29^{\circ}$. C, Responses of a binocular simple cell, recorded from the right hemisphere. Note that the responses through the left (nondeprived) eye (filled circles) were quite sharply tuned for orientation (half-width, $26^{\circ}$ ), while the responses through the right (deprived) eye (open circles) were nonselective.
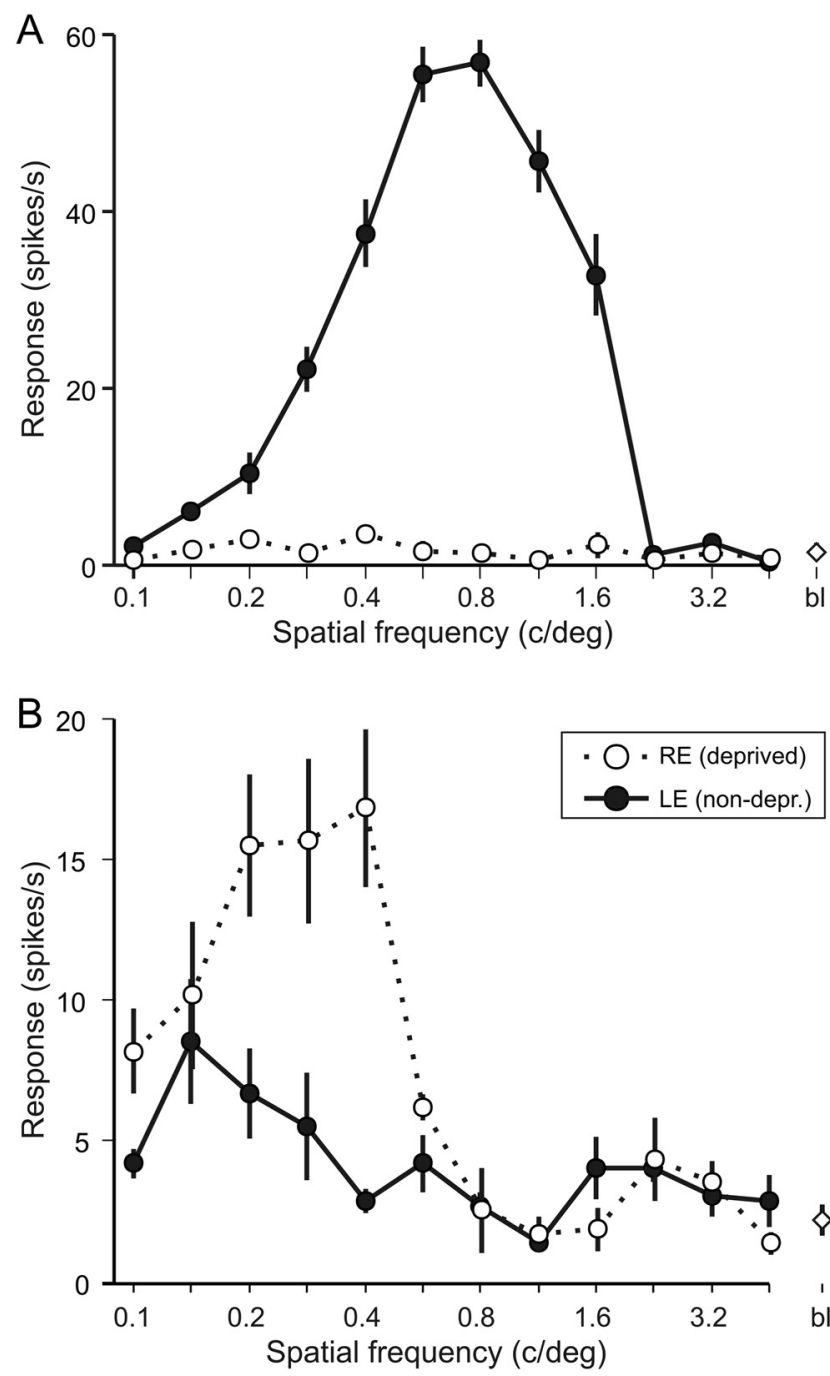

Figure 8. Spatial frequency tuning of single neurons recorded in the injected hemisphere. $\boldsymbol{A}$ Responses of a complex cell dominated by the left nondeprived (non-depr.) eye (LE) recorded from the left hemisphere. The filled circles represent the responses through the left eye, the open circles those through the right (deprived) eye. The open diamond on the right represents the spontaneous activity level in the presence of a blank screen. Error bars represent SEM. $\boldsymbol{B}$, Responses of a complex cell dominated by the right (deprived) eye (RE) recorded from the left hemisphere. Conventions are as in $\boldsymbol{A}$.

be either not present in adult cats at all or incapable of reversing processes that took place in early development.

While both glutamatergic and GABAergic receptors and their downstream signaling molecules undoubtedly play a crucial role in determining the time course of the critical period, in particular through the excitatory/inhibitory (E/I) balance (Hensch, 2005; Morishita and Hensch, 2008), the fact that their expression levels do not change greatly at the end of the critical period suggests that there are other factors limiting cortical plasticity beyond that point. The extracellular matrix is of particular interest since it changes from a largely soluble network of proteins during early postnatal development to an insoluble one in adolescence (Hockfield et al., 1990). In fact, the CSPG aggrecan was one of the first proteins to be identified whose expression profile is linked to the time course of the critical period. A particular glycosylation state of aggrecan (Matthews et al., 2002) is detected by the monoclonal antibody Cat-301 in perineuronal nets of specific neurons in the lateral geniculate nucleus (LGN) and visual cortex of cats and 
monkeys (Hockfield et al., 1983; Hendry et al., 1984), and its level of expression in the LGN is known to be regulated by visual experience (Sur et al., 1988). The onset of aggrecan expression in the cat visual cortex also correlates with the decline in experiencedependent plasticity at the end of the critical period, and dark rearing reversibly reduces aggrecan expression (Kind et al., 2012). Importantly, long-term MD does not cause decreased aggrecan expression (Kind et al., 2012); therefore, the ineffectiveness of chondroitinase treatment cannot be due to an already reduced CSPG expression that might otherwise have prevented recovery from MD. The relatively moderate effect of CSPG digestion in cats on cortical plasticity therefore suggests that other factors need to be tackled that prevent a better recovery from long-term MD.

First, there are additional structural barriers to adult plasticity, primarily myelin-related proteins that restrict axonal growth, such as NgR (McGee et al., 2005), and CSPG related proteins, such as cartilage link protein Crtll (Carulli et al., 2010). Their removal has so far only been shown in mice to restore OD plasticity. The only interventions in adult cats that induced an $\mathrm{OD}$ shift following MD are cultured astrocyte grafts (Müller and Best, 1989) and infusion of nerve growth factor (Gu et al., 1994; Galuske et al., 2000).

Second, there are numerous manipulations that later in life can restore plasticity by shifting the $\mathrm{E} / \mathrm{I}$ balance toward its state during the critical period, typically by decreasing inhibition. Examples of approaches that have proven successful in rodents include inhibiting the activity of the GABA-synthesizing enzyme glutamic acid decarboxylase (Harauzov et al., 2010), re-expression of the embryonic Otx2 homeoprotein in parvalbumin-positive cells in adult visual cortex (Sugiyama et al., 2008), treatment with the serotonin reuptake inhibitor fluoxetine (Maya Vetencourt et al., 2008), and enhancement of nicotinic acetylcholine receptor signaling (Morishita et al., 2010). Again, for cats evidence is limited, although manipulating the levels of neuromodulators such as acetylcholine and noradrenaline has been reported to be effective in restoring $\mathrm{OD}$ plasticity (Kasamatsu et al., 1985; Bear and Singer, 1986; Mataga et al., 1992). It is, however, worth noting that there has not been a single report yet of successful reversal of an MD-induced OD shift in cat visual cortex.

A third, entirely noninvasive approach to restoring vision to an amblyopic eye is to provide some form of environmental enrichment that induces increased sensory-motor stimulation. This has been shown to restore normal visual acuity in long-term MD rats through reduced GABAergic inhibition and decreased density of PNNs in the visual cortex (Sale et al., 2007).

All of the aforementioned brakes of plasticity appear to be very much interrelated. To improve the efficacy of chondroitinase as a treatment for amblyopia, a combination with other approaches should therefore be considered. In terms of recovery of function after spinal cord injuries, the combination of CSPG digestion by chondroitinase and task-specific motor rehabilitation has already demonstrated clear synergistic effects, presumably because newly grown connections facilitated by CSPG digestion are selectively strengthened or aberrant ones retracted during rehabilitation (García-Alías and Fawcett, 2012). With respect to amblyopia, a combination of chondroitinase treatment with visual tasks requiring binocular interaction (Waddingham et al., 2006; Li et al., 2009) may well be similarly effective. In addition, it may be feasible to make the chondroitinase treatment itself more effective by replacing direct injection with either slow release from a fibrin gel (Hyatt et al., 2010) or lentiviral expression (Zhao et al., 2011).

\section{References}

Attwell D, Laughlin SB (2001) An energy budget for signaling in the grey matter of the brain. J Cereb Blood Flow Metab 21:1133-1145. CrossRef Medline

Baro JA, Lehmkuhle S, Kratz KE (1990) Electroretinograms and visual evoked potentials in long-term monocularly deprived cats. Invest Ophthalmol Vis Sci 31:1405-1409. Medline

Bavelier D, Levi DM, Li RW, Dan Y, Hensch TK (2010) Removing brakes on adult brain plasticity: from molecular to behavioral interventions. J Neurosci 30:14964-14971. CrossRef Medline

Bear MF, Singer W (1986) Modulation of visual cortical plasticity by acetylcholine and noradrenaline. Nature 320:172-176. CrossRef Medline

Becker CG, Becker T (2002) Repellent guidance of regenerating optic axons by chondroitin sulfate glycosaminoglycans in zebrafish. J Neurosci 22 : 842-853. Medline

Berkley MA, Watkins DW (1973) Grating resolution and refraction in the cat estimated from evoked cerebral potentials. Vis Res 13:403-415. CrossRef Medline

Bonhoeffer T, Grinvald A (1993) The layout of iso-orientation domains in area 18 of cat visual cortex: optical imaging reveals a pinwheel-like organization. J Neurosci 13:4157-4180. Medline

Bonhoeffer T, Grinvald A (1996) Optical imaging based on intrinsic signal: the methodology. In: Brain mapping: the methods (Toga AW, Mazziotta JC, eds), pp 55-97. London: Academic.

Bonhoeffer T, Kim DS, Malonek D, Shoham D, Grinvald A (1995) Optical imaging of the layout of functional domains in area 17 and across the area 17/18 border in cat visual cortex. Eur J Neurosci 7:1973-1988. CrossRef Medline

Bradbury EJ, Moon LD, Popat RJ, King VR, Bennett GS, Patel PN, Fawcett JW, McMahon SB (2002) Chondroitinase ABC promotes functional recovery after spinal cord injury. Nature 416:636-640. CrossRef Medline

Campbell FW, Maffei L, Piccolino M (1973) The contrast sensitivity of the cat. J Physiol 229:719-731. Medline

Carulli D, Pizzorusso T, Kwok JCF, Putignano E, Poli A, Forostyak S, Andrews MR, Deepa SS, Glant TT, Fawcett JW (2010) Animals lacking link protein have attenuated perineuronal nets and persistent plasticity. Brain 133:2331-2347. CrossRef Medline

Celio MR, Spreafico R, De Biasi S, Vitellaro-Zuccarello L (1998) Perineuronal nets: past and present. Trends Neurosci 21:510-515. CrossRef Medline

Crair MC, Ruthazer ES, Gillespie DC, Stryker MP (1997) Relationship between the ocular dominance and orientation maps in visual cortex of monocularly deprived cats. Neuron 19:307-318. CrossRef Medline

Faulkner SD, Vorobyov V, Sengpiel F (2005) Limited protection of the primary visual cortex from the Effects of monocular deprivation by strabismus. Cereb Cortex 15:1822-1833. CrossRef Medline

Frenkel MY, Bear MF (2004) How monocular deprivation shifts ocular dominance in visual dortex of young mice. Neuron 44:917-923. CrossRef Medline

Frostig RD, Lieke EE, Ts'o DY, Grinvald A (1990) Cortical functional architecture and local coupling between neuronal activity and the microcirculation revealed by in vivo high-resolution optical imaging of intrinsic signals. Proc Natl Acad Sci U S A 87:6082-6086. CrossRef Medline

Galuske RA, Kim DS, Castrén E, Singer W (2000) Differential effects of neurotrophins on ocular dominance plasticity in developing and adult cat visual cortex. Eur J Neurosci 12:3315-3330. CrossRef Medline

García-Alías G, Fawcett JW (2012) Training and anti-CSPG combination therapy for spinal cord injury. Exp Neurol 235:26-32. CrossRef Medline

Gillespie DC, Crair MC, Stryker MP (2000) Neurotrophin-4/5 alters responses and blocks the effect of monocular deprivation in cat visual cortex during the critical period. J Neurosci 20:9174-9186. Medline

Gu Q, Liu Y, Cynader MS (1994) Nerve growth factor-induced ocular dominance plasticity in adult cat visual cortex. Proc Natl Acad Sci U S A 91: 8408-8412. CrossRef Medline

Guimarães A, Zaremba S, Hockfield S (1990) Molecular and morphological changes in the cat lateral geniculate nucleus and visual cortex induced by visual deprivation are revealed by monoclonal antibodies Cat-304 and Cat-301. J Neurosci 10:3014-3024. Medline

Harauzov A, Spolidoro M, DiCristo G, De Pasquale R, Cancedda L, Pizzo- 
russo T, Viegi A, Berardi N, Maffei L (2010) Reducing intracortical inhibition in the adult visual cortex promotes ocular dominance plasticity. J Neurosci 30:361-371. CrossRef Medline

Harris LR (1978) Contrast sensitivity and acuity of a conscious cat measured by the occipital evoked potential. Vis Res 18:175-178. CrossRef Medline

Hendry SHC, Hockfield S, Jones EG, McKay R (1984) Monoclonal antibody that identifies subsets of neurones in the central visual system of monkey and cat. Nature 307:267-269. CrossRef Medline

Hensch TK (2005) Critical period plasticity in local cortical circuits. Nat Rev Neurosci 6:877-888. CrossRef Medline

Hockfield S, McKay RD, Hendry SHC, Jones EG (1983) A surface antigen that identifies ocular dominance columns in the visual cortex and laminar features of the lateral geniculate nucleus. Cold Spring Harb Symp Quant Biol 48:877-889. CrossRef Medline

Hockfield S, Kalb RG, Zaremba S, Fryer H (1990) Expression of neural proteoglycans correlates with the acquisition of mature neuronal properties in the mammalian brain. Cold Spring Harb Symp Quant Biol 55:505-514. CrossRef Medline

Howarth CM, Vorobyov V, Sengpiel F (2009) Interocular transfer of adaptation in the primary visual cortex. Cereb Cortex 19:1835-1843. CrossRef Medline

Hubel DH, Wiesel TN (1962) Receptive fields, binocular interaction and functional architecture in the cat's visual cortex. J Physiol 160:106-154. Medline

Hyatt AJT, Wang D, Kwok JC, Fawcett JW, Martin KR (2010) Controlled release of chondroitinase $\mathrm{ABC}$ from fibrin gel reduces the level of inhibitory glycosaminoglycan chains in lesioned spinal cord. J Control Release 147:24-29. CrossRef Medline

Jaffer S, Vorobyov V, Kind PC, Sengpiel F (2012) Experience-dependent regulation of functional maps and synaptic protein expression in the cat visual cortex. Eur J Neurosci 35:1281-1294. CrossRef Medline

Kasamatsu T, Watabe K, Heggelund P, Schöller E (1985) Plasticity in cat visual cortex restored by electrical stimulation of the locus coeruleus. Neurosci Res 2:365-386. CrossRef Medline

Kind PC, Sengpiel F, Beaver CJ, Crocker-Buque A, Kelly GM, Matthews RT, Mitchell DE (2012) The development and activity-dependent expression of aggrecan in the cat visual cortex. Cereb Cortex. Advance online publication. Retrieved December 4, 2012. doi:10.1093/cercor/bhs015. CrossRef

Laabs T, Carulli D, Geller HM, Fawcett JW (2005) Chondroitin sulfate proteoglycans in neural development and regeneration. Curr Opin Neurobiol 15:116-120. CrossRef Medline

Lander C, Kind P, Maleski M, Hockfield S (1997) A family of activitydependent neuronal cell-surface chondroitin sulfate proteoglycans in cat visual cortex. J Neurosci 17:1928-1939. Medline

Li R, Polat U, Makous W, Bavelier D (2009) Enhancing the contrast sensitivity function through action video game training. Nat Neurosci 12:549-551. CrossRef Medline

Lin R, Kwok JCF, Crespo D, Fawcett JW (2008) Chondroitinase ABC has a long-lasting effect on chondroitin sulphate glycosaminoglycan content in the injured rat brain. J Neurochem 104:400-408. CrossRef Medline

Mataga N, Imamura K, Watanabe Y (1992) 1-Threo-3,4-Dihydroxyphenylserine enhanced ocular dominance plasticity in adult cats. Neurosci Lett 142: 115-118. CrossRef Medline

Matthews RT, Kelly GM, Zerillo CA, Gray G, Tiemeyer M, Hockfield S (2002) Aggrecan glycoforms contribute to the molecular heterogeneity of perineuronal nets. J Neurosci 22:7536-7547. Medline

Maya Vetencourt JF, Sale A, Viegi A, Baroncelli L, De Pasquale R, O'Leary F, Castrén E, Maffei L (2008) The antidepressant fluoxetine restores plasticity in the adult visual cortex. Science 320:385-388. CrossRef Medline

McGee AW, Yang Y, Fischer QS, Daw NW, Strittmatter SM (2005) Experience-driven plasticity of visual cortex limited by myelin and Nogo receptor. Science 309:2222-2226. CrossRef Medline

Mitchell DE (1991) The long-term effectiveness of different regimens of occlusion on recovery from early monocular deprivation in kittens. Phil Trans R Soc Lond B Biol Sci 333:51-79. CrossRef Medline

Mitchell DE, Murphy KM, Kaye MG (1984) Labile nature of the visual recovery promoted by reverse occlusion in monocularly deprived kittens. Proc Natl Acad Sci U S A 81:286-288. CrossRef Medline
Mitchell DE, Gingras G, Kind PC (2001) Initial recovery of vision after early monocular deprivation in kittens is faster when both eyes are open. Proc Natl Acad Sci U S A 98:11662-11667. CrossRef Medline

Mizuguchi S, Uyama T, Kitagawa H, Nomura KH, Dejima K, GengyoAndo K, Mitani S, Sugahara K, Nomura K (2003) Chondroitin proteoglycans are involved in cell division of Caenorhabditis elegans. Nature 423:443-448. CrossRef Medline

Monnier PP, Sierra A, Schwab JM, Henke-Fahle S, Mueller BK (2003) The Rho/ROCK pathway mediates neurite growth-inhibitory activity associated with the chondroitin sulfate proteoglycans of the CNS glial scar. Mol Cell Neurosci 22:319-330. CrossRef Medline

Morishita H, Hensch TK (2008) Critical period revisited: impact on vision. Curr Opin Neurobiol 18:101-107. CrossRef Medline

Morishita H, Miwa JM, Heintz N, Hensch TK (2010) Lynx1, a cholinergic brake, limits plasticity in adult visual cortex. Science 330:1238-1240. CrossRef Medline

Müller CM, Best J (1989) Ocular dominance plasticity in adult cat visual cortex after transplantation of cultured astrocytes. Nature 342:427-430. CrossRef Medline

Murphy KM, Mitchell DE (1986) Bilateral amblyopia after a short period of reverse occlusion in kittens. Nature 323:536-538. CrossRef Medline

Pizzorusso T, Medini P, Berardi N, Chierzi S, Fawcett JW, Maffei L (2002) Reactivation of ocular dominance plasticity in the adult visual cortex. Science 298:1248-1251. CrossRef Medline

Pizzorusso T, Medini P, Landi S, Baldini S, Berardi N, Maffei L (2006) Structural and functional recovery from early monocular deprivation in adult rats. Proc Natl Acad Sci U S A 103:8517-8522. CrossRef Medline

Properzi F, Fawcett JW (2004) Proteoglycans and brain repair. News Physiol Sci 19:33-38. CrossRef Medline

Ranson A, Cheetham CEJ, Fox K, Sengpiel F (2012) Homeostatic plasticity mechanisms are required for juvenile, but not adult, ocular dominance plasticity. Proc Natl Acad Sci U S A 109:1311-1316. CrossRef Medline

Sale A, Maya Vetencourt JF, Medini P, Cenni MC, Baroncelli L, De Pasquale R, Maffei L (2007) Environmental enrichment in adulthood promotes amblyopia recovery through a reduction of intracortical inhibition. Nat Neurosci 10:679-681. CrossRef Medline

Sato M, Stryker MP (2008) Distinctive features of adult ocular dominance plasticity. J Neurosci 28:10278-10286. CrossRef Medline

Sawtell NB, Frenkel MY, Philpot BD, Nakazawa K, Tonegawa S, Bear MF (2003) NMDA receptor-dependent ocular dominance plasticity in adult visual cortex. Neuron 38:977-985. CrossRef Medline

Schwarzkopf DS, Vorobyov V, Mitchell DE, Sengpiel F (2007) Brief daily binocular vision prevents monocular deprivation effects in visual cortex. Eur J Neurosci 25:270-280. CrossRef Medline

Sharma K, Selzer ME, Li S (2012) Scar-mediated inhibition and CSPG receptors in the CNS. Exp Neurol 237:370-378. CrossRef Medline

Silver J, Miller JH (2004) Regeneration beyond the glial scar. Nat Rev Neurosci 5:146-156. CrossRef Medline

Snyder A, Shapley R (1979) Deficits in the visual evoked potentials of cats as a result of visual deprivation. Exp Brain Res 37:73-86. CrossRef Medline

Stewart CE, Moseley MJ, Fielder AR (2011) Amblyopia therapy: an update. Strabismus 19:91-98. CrossRef Medline

Sugiyama S, Di Nardo AA, Aizawa S, Matsuo I, Volovitch M, Prochiantz A, Hensch TK (2008) Experience-dependent transfer of Otx2 homeoprotein into the visual cortex activates postnatal plasticity. Cell 134:508-520. CrossRef Medline

Sur M, Frost DO, Hockfield S (1988) Expression of a surface-associated antigen on Y-cells in the cat lateral geniculate nucleus is regulated by visual experience. J Neurosci 8:874-882. Medline

Waddingham PE, Butler TKH, Cobb SV, Moody ADR, Comaish IF, Haworth SM, Gregson RM, Ash IM, Brown SM, Eastgate RM, Griffiths GD (2006) Preliminary results from the use of the novel interactive binocular treatment (I-BiT) system, in the treatment of strabismic and anisometropic amblyopia. Eye 20:375-378. CrossRef Medline

Zhao RR, Muir EM, Alves JN, Rickman H, Allan AY, Kwok JC, Roet KC, Verhaagen J, Schneider BL, Bensadoun JC, Ahmed SG, Yáñez-Muñoz RJ, Keynes RJ, Fawcett JW, Rogers JH (2011) Lentiviral vectors express chondroitinase $\mathrm{ABC}$ in cortical projections and promote sprouting of injured corticospinal axons. J Neurosci Methods 201:228-238. CrossRef Medline 